\title{
EDITORAS UNIVERSITÁRIAS uma contribuição à indústria ou à artesania cultural?
}

\author{
Maria do Carmo Guedes \\ Diretora da Editora da PUC-SP, Professora da Faculdade de Psicologia e do Programa \\ de Estudos Pós-Graduados em Psicologia Social da PUC-SP \\ Maria Eliza Mazzilli Pereira \\ Vice-diretora da Editora da PUC-SP e Professora da Faculdade de Psicologia da PUC-SP
}

\begin{abstract}
Resumo: Rápida apresentação do que a parca literatura na área oferece mostra a diversidade de interpretações para o que deve e pode estar sendo a publicação institucional da/na universidade brasileira. São Paulo parece ter, nesse contexto, uma posição peculiar - inferida de uma rápida comparação das editoras paulistas com as editoras da UnB e UFSC. Segue-se uma análise de sua contribuição à educação - com base na leitura de catálogos e entrevista com responsáveis por editoras universitárias, institucionais ou comerciais. Completam o texto considerações sobre um possível papel educacional das editoras universitárias institucionais para além da publicação de textos para a área educacional.

Palavras-chave: publicação universitária; universidades brasileiras; administração educacional.
\end{abstract}

A nálise rápida do conjunto das Editoras Universitárias ${ }^{1}$ brasileiras mostra bem a diversidade de interpretações para o que pode ou deve ser a editoração institucional da/na Universidade.

Catálogo de 1987, elaborado para a primeira participação do conjunto dessas Editoras na Bienal Internacional do Rio de Janeiro permite observar como se fazia, à época, a inserção das editoras no organograma de suas instituições: ligadas a uma das pró-reitorias (acadêmica, administrativa ou de extensão) ou subordinadas ao reitor, diretamente ou por intermédio da chefia de gabinete, ou, mais raramente, ao diretor de uma unidade, acadêmica (um Conselho Editorial ou um dos Centros) ou não (uma coordenadoria de órgão suplementar); setor administrativo, tipo "imprensa universitária", ou setor acadêmico, dirigido por professor, ou, ainda, de responsabilidade de um diretor subordinado a uma fundação; dirigidas por pessoal da área acadêmica ou administrativa da Universidade, ou por editores especialmente contratados; setor exclusivo para edição de livros e/ou revistas ou integrado à gráfica, respondendo por toda a papelaria da instituição; ou atividade voltada ao ensino e pesquisa em editoração. Assim, integrando diretores de órgão complementar ou suplementar, do quadro acadêmico ou administrativo, ou mesmo estranhos a ele, editores, escritores, gráficos, administradores, contadores e professores das mais diversas áreas (literatura, arquitetura, biblioteconomia, jorna- lismo, psicologia, física), as Editoras Universitárias encontraram-se no seu terceiro Seminário Nacional, em Salvador, em 1985, quando foi decidida a participação conjunta, na Reunião Anual da SBPC, em Curitiba, e na Bienal Internacional do Livro, em São Paulo, em 1986. Nesse Seminário, também foi aprovada a idéia de criação de uma associação nacional, o que veio a ocorrer em 1987, no Seminário de Goiânia.

Essas Editoras foram instaladas no bojo da ditadura. Tendo na origem a imprensa oficial, a maioria das Editoras federais mais antigas data dos anos 70 , sendo que sua expansão foi resultado da confluência de dois interesses: dos diretores das gráficas de universidades federais, que desde 1976 se reuniam (Da Costa, 1992) para debater temas como padronização dos impressos, custos, melhor aproveitamento dos equipamentos; e do MEC, que em 1981 criou um programa especial, o Proedi, ${ }^{2}$ para "estimular a publicação da produção científica e intelectual das IES, tanto para fomentar o debate crítico (...) como para dar o imprescindível apoio ao avanço do desenvolvimento científico e tecnológico nacional". Responsável pela publicação de uma farta literatura, em geral de pesquisa, voltada a problemas regionais, até 1987, ano da criação da Abeu (Associação Brasileira das Editoras Universitárias), este programa atendia apenas às editoras do sistema federal.

Algumas curiosidades podem ainda ser acrescentadas para completar esta rápida descrição: ${ }^{3}$ a Editora da Uni- 
versidade Federal de Santa Catarina foi, durante muito tempo, se não a única, pelo menos a principal editora do Estado; uma Editora do interior do Rio Grande do Sul lançou, no final dos anos 80, um programa para incentivar e descobrir talentos na escola fundamental, ao verificar que há mais de 50 anos não se publicava nenhum escritor da cidade; em 1998, no Salão Internacional do Livro, em São Paulo, oito Editoras da região Nordeste lançaram uma coleção que recupera escritores da região, importantes mas "esquecidos"; a Editora da UFPa não tinha conselho editorial e era dirigida pelo gráfico responsável pela imprensa universitária, quando começou a publicar Platão em primorosas traduções diretamente do grego; em 1986, no Seminário Nacional das Editoras Universitárias, realizado em Campinas, uma das principais atividades foi uma mesa que reuniu editores de empresas comerciais (Record e EPU) para debate com editores das Editoras Universitárias (Editora UnB e Educ); em 1987/88, a Câmara Brasileira do Livro - CBL tinha um grupo de editores universitários de empresas privadas (o GEU) que recebeu em seu quadro uma representação da recém-criada Abeu; muito antes da criação da Abeu, as Editoras já tinham um projeto para distribuição de suas publicações - o Programa Inter-universitário para Distribuição do Livro (PIDL), responsável pela instalação de uma grande parte das livrarias universitárias das IES federais (condição para participação no Programa); a Editora da PUC-SP, do mesmo modo que muitas outras, iniciou suas atividades com um procedimento que incluía apenas dois passos: selecionar as obras e repassá-las, para edição, a editoras privadas, publicando, em seus primeiros quatro anos, nessa condição, apenas livros na área de Direito.

Além de completar o quadro da diversidade possível, estes exemplos parecem mostrar também a liberdade dos editores em seu trabalho. Porém, o que dizem seus diretores sobre o papel e a função das Editoras Universitárias? À diversidade que vivem, será que corresponde também alguma variedade no que se refere aos objetivos que devam ser os das Editoras?

Para lidar apenas com o que tem sido publicado, citam-se alguns exemplos retirados de publicação que traz as conferências e debates do Seminário Nacional das Editoras Universitárias de 1986. Destacando em especial suas diferenças em relação às universitárias não institucionais, os representantes das Editoras Universitárias lembram sempre sua "função cultural", mas especificam ainda: seu papel de "extensão do ensino e da pesquisa" (Rodrigues, 1986); o compromisso com a "produção e tradução de li- vros-texto" (Azevedo, 1986); com a promoção de edições experimentais (Pinsky, 1986); "elo de ligação entre os canais geradores do saber" nas universidades (Costa, 1986); a possibilidade de contribuir de forma efetiva com o ensino através de obras dirigidas (Costa, 1986); divulgação da produção intelectual (artística, literária, científica, tecnológica) do corpo docente da Universidade a que serve (Campos, 1986).

Cinco ou seis anos depois, segundo Bufrem (1990) e Da Costa (1992) muitas Editoras têm nova direção, mas de modo geral pensa-se ainda o mesmo, como Edison Rodrigues Lima (1989), então presidente da Abeu; outros destacam alguns aspectos, se não inteiramente novos, agora colocados de outro modo. Em 1991, provocada possivelmente apenas por alterações que ocorreram na Editora da USP, a "sociedade" também se manifesta: o jornal O Estado de S. Paulo (apud Da Costa, 1992:15) afirma, em editorial intitulado "Editoras e Universidades", que "a definição de uma política editorial é sinal evidente do rumo que uma instituição pretende seguir. Aliás, nestes tempos em que há tantos privilégios exclusivos prometidos à pesquisa aplicada como salvação nacional, definir o que deve ser publicado em uma editora universitária ganha importância capital. Esse debate não pode mais ser adiado".

Entretanto, qualquer que seja a função atribuída a uma Editora Universitária, seu entendimento necessita ainda de mais uma análise. É preciso situar a Editora em seu tempo e espaço, de modo a saber se sua função não estaria já sendo atendida.

De novo, a Editora da UFSC como exemplo: seu diretor por mais de dez anos foi um escritor reconhecido, ${ }^{4}$ contratado diretamente pela Fundação mantenedora da Editora e Gráfica da Universidade, que pensava, como atribuição da Editora Universitária, um "papel complementar ao das editoras comerciais" (Miguel, 1986). E publicava para a Universidade (sua coleção de textos para a graduação em Física, Química, Lingüística, etc. tem sido best seller entre os livros das Editoras Universitárias na Bienal do Livro em São Paulo desde 1986), bem como ficção e poesia de autores que nada tinham a ver com a universidade. O que teria Salim Miguel a dizer hoje, ou se fosse convidado para dirigir uma Editora Universitária em São Paulo?

Das 1.184 editoras registradas no Anuário Editorial Brasileiro de 1998, 563 são de São Paulo, sendo que 90\% destas localizam-se na capital. Provavelmente, num contexto como este, Editoras Universitárias devem ter mais 
liberdade para decidir suas atribuições. Entretanto, não teriam elas mais dificuldade para defender sua importância tanto junto às instituições de que fazem parte quanto frente às editoras privadas com as quais poderiam eventualmente estar competindo? Por outro lado, que liberdade há para um editor institucional dirigido ou orientado por um conselho editorial escolhido por critérios nem sempre "editoriais"?

Qualquer tentativa de responder a questões como estas começará sempre com o condicional "depende." Porém, pode ser que se chegue a uma só resposta: é no seu projeto editorial que uma Editora Universitária pode se mostrar mais, ou menos, defensável. É no seu projeto editorial que se pode saber a que veio.

\section{O CASO DA EDUCAÇÃO NOS PROJETOS DAS EDITORAS UNIVERSITÁRIAS}

A vocação das Editoras Universitárias parece estar, hoje, indissoluvelmente ligada à vocação educacional da universidade e elas têm exercido esse trabalho em educação de múltiplas formas. A mais previsível delas - e, por isso, a primeira que será abordada aqui - diz respeito àquilo que é publicado na área. Ao se falar da área, verifica-se que a própria forma de se reportar a ela já aponta a multiplicidade de contribuições possíveis: trata-se de publicações sobre educação? em educação? para educação?

Comecemos pelo que poderia ser chamado de publicações sobre educação. Neste tema, Editoras Universitárias têm, talvez, a sua maior tradição, seguindo aquela que é também a das universidades que lhes dão origem, isto é, a de produzir reflexões (sejam gerais ou sobre aspectos específicos) a respeito das diferentes áreas do saber. São muitas as publicações que analisam diferentes aspectos ligados à educação: educação e sociedade, ensino, aprendizagem, formação de professores, leitura, escrita, educação especial, mulher e educação, educação física, empregabilidade e educação, educação ambiental, trabalho docente, escola pública, alfabetização, educação de trabalhadores, currículo, pré-escola, Estado e educação, livro didático.

Uma preocupação recorrente refere-se à recuperação histórica da própria educação, de maneira geral, ou da educação brasileira, ou de algum aspecto particular da educação. Ilustrações disso são títulos como: História da pedagogia; História das universidades; Igreja e educação feminina (1859-1919); Memórias da educação - Campinas (1850-1960); História da instrução pública no Bra- sil (1500-1889); Universidade e compromisso social - a experiência da reforma da PUC, para ficarmos em exemplos das Editoras paulistas.

Um tema com forte presença nas publicações diz respeito a uma espécie de auto-análise da universidade, podendo se tratar da análise da universidade em geral ou de experiências específicas. São exemplos do primeiro caso títulos como: Identidade e transformação - o professor na universidade brasileira; A universidade desafiada; $A u$ tonomia universitária; História das universidades; O ideal da universidade. São exemplos do segundo caso: USP 1968-1969; Um passado revisitado - 80 anos do curso de filosofia da PUC-SP; O comportamento acadêmico nos cursos de graduação da Unicamp.

As publicações abordadas até aqui têm em comum o fato de constituírem análises sobre problemas ligados à educação, de caráter mais geral ou específico, porém sem uma preocupação com o uso pedagógico imediato, acompanhando uma cultura que, em geral, é das próprias universidades, no sentido de valorizar reflexões sobre diferentes temas, talvez mais que a produção de material "didático" sobre eles.

No entanto, mais recentemente, tem surgido - acompanhando uma tendência das universidades do exterior - a preocupação com a publicação de obras facilitadoras do trabalho do professor universitário em sala de aula. Nesse caso, não se trata de livros sobre educação, mas em, ou, talvez, para educação. São obras de caráter introdutório a diferentes áreas do conhecimento, que significam uma contribuição das Editoras Universitárias ao ensino. Introdução à economia; Introdução à filosofia política; Introdução à análise do discurso; Introdução à história da matemática; Introdução aos mecanismos de resistência mecânica são exemplos de títulos que aparecem entre as publicações dessas Editoras. A Educ, por exemplo, tem na sua linha editorial uma série - Trilhas - que publica "ensaios introdutórios sobre temas ou matérias constantes dos currículos de graduação ou de pós-graduação oferecidos pela PUC-SP, cujos autores são professores da PUC-SP ou de outras universidades do Brasil", possuindo títulos como: Planejamento de pesquisa; Psicologia; Entrevista e ética; Educação física; Crítica genética.

Um outro tipo de publicação das Editoras Universitárias para a educação corresponde aos livros didáticos para acompanhamento de cursos, que surgem da preocupação de professores em escrever para seus alunos. Talvez todas tenham alguns títulos nessa categoria, mas há as que formalizam este compromisso no seu projeto editorial, 
como a Editora da UFSC, com sua série de textos para a graduação, em diferentes áreas, e a Eduem (Editora da Universidade Estadual de Maringá), cuja série Apontamentos visa "possibilitar aos docentes o material de apoio didático-pedagógico, usado em sala de aula". Além disso, embora com menor freqüência, algumas Editoras Universitárias têm publicado obras com caráter didático para outros níveis de ensino que não o universitário.

Uma outra vertente de publicações que tem se tornado comum entre as Editoras Universitárias trata do ensino das diversas matérias. Essas publicações parecem acompanhar a formação, nas Universidades, de núcleos, nas diferentes áreas, preocupados com o seu ensino. Dessa forma, na PUC, por exemplo, acompanhando os trabalhos do núcleo de estudos sobre Educação Matemática, surgiram publicações como Educação Matemática. Uma introdução e até a revista Educação matemática pesquisa. Têm sido freqüentes títulos como: A filosofia e seu ensino; Ensino de serviço social: polêmicas; Ensino de segunda língua: redescobrindo as origens; Português instrumental: uma abordagem para o ensino de língua materna; Ensino das artes nas universidades; Ensino e aprendizagem nas escolas médicas.

Ainda sobre aquilo que é publicado, deve-se salientar um tipo de texto que não parece se encaixar em nenhuma das categorias mencionadas, mas que não pode deixar de ser considerado uma contribuição para a educação. Trata-se da inclusão, na linha editorial, de obras cuja finalidade é propiciar a reflexão, contrapor opiniões e fornecer uma abordagem multidisciplinar de diferentes temas, favorecendo o desenvolvimento do pensamento crítico do leitor e a ampliação da maneira de encarar determinado objeto de estudo. Mencionam-se, como exemplos, duas coleções que fazem parte da linha editorial da Educ: Contraponto e Eventos. A primeira publica "títulos que abalem áreas consagradas ou contenham material inovador e desviante, forçando o leitor a pensar aquilo que é tido como consensualmente aceito"; a segunda inclui coletâneas temáticas resultantes de eventos, sempre multidisciplinares e com autores de diferentes instituições.

É importante ressaltar, também, outros tipos de contribuição das Editoras Universitárias, que não dizem respeito diretamente àquilo que publicam, aos temas que são objeto de suas obras, como, por exemplo, a formação do leitor.

A preocupação com a qualidade do que é publicado concretiza essa função educacional importante das Editoras Universitárias. A facilidade de acesso a especialistas das diversas áreas do conhecimento, que atuam como seus assessores, fornecendo cuidadosa avaliação dos textos submetidos à apreciação para publicação, aliada à possibilidade que essas Editoras têm, pelo seu vínculo institucional, de fazer da excelência do material a ser publicado o critério primeiro para sua aceitação, ao qual se submete o critério comercial, tem permitido o lançamento de obras de alta qualidade acadêmica, de pesquisas pioneiras, de teorizações inovadoras, de reflexões originais. À medida que a divulgação das obras publicadas tem alcançado uma amplitude cada vez maior, estas vêm se tornando instrumentos de circulação do saber produzido nas universidades, contribuindo para o desenvolvimento da reflexão do leitor, para o diálogo entre especialistas.

Porém, as Editoras Universitárias podem estar formando não só o leitor, mas também o autor, uma vez que a proximidade de acesso à publicação daquilo que produzem, a seleção rigorosa do material a ser publicado, o fato de contar com os especialistas das várias áreas, que apontam alterações necessárias para melhorar a qualidade do texto não só do ponto de vista acadêmico, mas também editorial, fazem das Editoras um filtro importante para o trabalho dos professores, um incentivo para que escrevam e para que escrevam melhor. José Castilho Marques Neto, diretor da editora da Unesp, lembra um professor que, tendo um material para publicação, afirmava que seu texto ainda não estava pronto para ser publicado pela editora da Universidade.

Algumas experiências chegaram mesmo a ser propostas por Editoras Universitárias para favorecer a formação de autores. A Educ já teve (1986-88) em sua linha editorial uma coleção de material "pré-print" - subdividida em séries: Apoio ao ensino; Apoio à pesquisa; Apoio ao autor - oferecida "como oportunidade especial para o pesquisador ouvir colegas enquanto pesquisa, ou enquanto redige artigo ou livro a ser enviado para publicação; para o autor novo experimentar suas asas; para o autor experimentado debater idéias antes mesmo de lhes dar forma final; e para o professor substituir fotocópia indiscriminada de material escrito para sala de aula". Revisto, o projeto tem hoje a forma de um Banco de Artigos para liberação sob demanda, "abrindo ao autor um novo canal para difusão de seus trabalhos e trazendo ao leitor material importante à sua atividade como professor, pesquisador, estudante". Também foi criado nessa Editora o selo Aluno-autor, sob o qual se publicam, na forma de coletâneas organizadas e prefaciadas por professor, "excelentes trabalhos de fim de semestre" ou relatórios de pesquisa de iniciação científica. São materiais submetidos a dois ti- 
pos de seleção, editorial e de área, como qualquer material da Editora. Também a Editora da Unesp desenvolve um projeto - os Laboratórios Editoriais -, cuja preocupação é incentivar a publicação nos diferentes campi da Universidade e contribuir para a formação de autores. Embora o material aí publicado não leve o selo da Editora, tem a sua orientação e a Editora também facilita sua distribuição e venda. Cabe citar ainda o projeto "Espaço Educ", que traz para a Universidade "a cada semana uma Editora diferente". Pensado como espaço para atualização na área do livro, tem também como objetivo propiciar aos autores uma apreciação das editoras e seus projetos, ampliando seus conhecimentos sobre onde publicar.

Além de leitores e autores, as Editoras Universitárias formam editores científicos; e o fazem de maneiras diferentes, dependendo do projeto editorial de cada uma. Algumas, além de apoiar a publicação das revistas científicas dos diversos setores da Universidade, desde que se adaptem a uma padronização no formato e/ou satisfaçam determinadas condições, sobretudo no que concerne à manutenção de periodicidade e à indexação, desenvolvem um trabalho de acompanhamento e orientação de editores científicos em decisões que contribuem para a qualidade editorial exigida pela comunidade científica; outras chegam a promover eventos, cursos, oficinas para editores e professores sobre o trabalho editorial e sobre direitos autorais. Outras promovem encontros entre os editores de revistas e com representantes de órgãos como a Abec (Associação Brasileira de Editores Científicos) e agências financiadoras na área de publicação. Há ainda uma ou duas que se preocupam em aproximar os editores de catalogadores, indexadores, distribuidores e livreiros e várias que procuram favorecer a relação dos editores das revistas com as bibliotecas da sua Universidade, em atenção ao sistema de permutas de periódicos.

Finalmente, as Editoras Universitárias contribuem para a formação em edição. A Educ, por exemplo, tem oferecido, aos estudantes dos cursos de Língua Portuguesa, oportunidade para trabalhar revisão de texto, com acompanhamento do pessoal da própria editora, além de estágio para estudantes de outras áreas que têm o texto e a imagem como objetos centrais de trabalho - Jornalismo e Publicidade. Já a "Escola do Livro", projeto da parceria Editora Unesp/Câmara Brasileira do Livro, oferece desde 1999 uma variada relação de cursos, com certificado expedido pela Pró-Reitoria de Extensão da Unesp, em áreas que vão desde leitura, redação e revisão de textos, até treinamento em vendas.
As Editoras Universitárias vêm, assim, ampliando sua atuação vinculada à educação e têm mesmo, à medida que se afirmam como centros difusores do conhecimento produzido nas Universidades ou de material relevante para o ensino e o debate acadêmico, contribuído para a própria afirmação institucional das Universidades.

\section{DO AMADORISMO À PROFISSIONALIZAÇÃO}

Desde sua instalação, a Abeu tem cobrado - e contribuído para - uma maior profissionalização de suas afiliadas. Quem viu a exposição das Editoras em 1986 no Ibirapuera e as dos últimos anos no Center Norte sabe falar do sucesso desse projeto. Entrevistando o pessoal que tem respondido pela presença da Abeu em eventos internacionais (Feiras do Livro Universitário no país e na América Latina, além das Bienais do Livro do Rio e de São Paulo), verifica-se também a crescente profissionalização na seleção e quantidade dos livros a enviar, quando em 1986 e 1988 parecia que eram apenas oportunidades para "limpar estoque". De todo modo, de que profissionalização se está falando?

Entre as exigências para filiar-se à Abeu, seu primeiro Estatuto já colocava a de ter Conselho Editorial, visando tornar os editores conscientes de sua diferença em relação às editoras privadas. Partilhar, ou mesmo deixar a um Conselho de professores da Universidade, as decisões sobre o que publicar seria uma forma de tornar a produção das Editoras uma produção $d a$ Universidade. Confirmada quando da revisão do Estatuto em 1999, esta exigência não tem sido, em verdade, devidamente cobrada, assim como não se tem cobrado que, para se filiar, a Editora tenha que estar ligada a uma IES. Das 86 Editoras que são hoje filiadas à Abeu, apenas 66 são de IES, sendo que as outras pertencem a outro tipo de instituição, em geral institutos de pesquisa em busca de distribuição para suas publicações, ou unidades isoladas de ensino técnico.

Entre os objetivos colocados desde o primeiro Estatuto, um referia-se à preocupação com a qualidade gráfica dos livros - recém-observada em seu conjunto quando expostos na SBPC e na Bienal do Livro em São Paulo, em 1986. Se o estande das Editoras Universitárias, nesse ano, foi bem visitado e se vendeu muito bem, em especial na Bienal, em agosto, isso se deveu muito mais ao ocaso do Plano Cruzado do que ao chamariz de um material atraente ou bem feito. A montagem do primeiro catálogo coletivo (1988) reduziu-se a uma apresentação de títulos por área de conhecimento, porque não se conseguiu para todas uma descrição, rápida que fosse, de seus 
projetos. Assim, todos os Seminários que se seguiram têm oferecido cursos e oficinas sobre os mais diversos aspectos da produção editorial, além de palestras e debates especiais sobre custos, distribuição e direitos autorais.

No que se refere aos projetos editoriais, uma das ocupações da Abeu tem sido a de incentivar co-edições entre as Editoras, seja para aproximá-las, favorecendo a troca de informações e conhecimentos, seja para partilhar material entre as Universidades, ampliando a difusão do saber produzido ou atendendo à tendência de publicações que reúnam autores de diferentes instituições. Agrupadas por região, as Editoras tiveram oportunidades de encontro mais ou menos freqüentes, em geral muito produtivos. O sucesso mais recente é o da região Nordeste, com sua Coleção Nordestina, que já publicou 14 volumes.

Entretanto, muito da editoração universitária lembra mais a "artesania editorial" a que se referem Creni (1997), quando fala dos "pequenos editores" da década de 50, tão atentos à seleção do material a publicar como da qualidade gráfica do livro, e Stumpf (1994) que, ao discutir como se estrutura o sistema de produção das revistas universitárias, chama-as de projetos inacabados. São exemplos do primeiro tipo títulos como Por amor às cidades, de preciosa coleção da Editora da Unesp, a publicação dos Contos de Grimm em edição bilíngüe português/alemão da UFCS e o livro para crianças publicado pela Edunisc (Editora da Universidade de Santa Cruz do Sul), que traz Grimm, Perrault e Basile em português e, respectivamente, alemão, francês e italiano; ou ainda a edição crítica da Educ, de livro publicado no Brasil em francês em 1889, Instrução pública no Brasil, 1500-1889. História e legislação, além do recém-lançado Imagens de magia e de ciência: entre o simbolismo e os diagramas da razão. Quanto aos periódicos científicos, é importante lembrar que dependem do trabalho de edição científica que nunca é suficientemente valorizado, nem pelas agências de avaliação do trabalho acadêmico e, freqüentemente, nem mesmo pelos autores; e que, mais ainda que os livros, precisam sempre ser subsidiados.

Submetidas aos projetos das instituições a que se filiam, as Editoras Universitárias, salvo talvez apenas duas bem conhecidas exceções - a Editora da Unesp e a Editora da UnB - têm hoje sua direção alterada a cada mudança de reitor. Além da descontinuidade que isto pode provocar em sua linha editorial, a impressão que se tem é que, a cada encontro, a Abeu precisa "começar tudo de novo". Porém, se imprensa e edição na universidade têm que, ou podem, ser projetos de sua política educacional e cultural, como torná-los ao mesmo tempo projetos que não possam ser simplesmente fechados porque não são do gosto do próximo diretor ou porque este tem seus próprios projetos (não é raro que diretor de Editora Universitária seja diretor também, ou ex-editor, de editora privada)?

Os conselhos editoriais das Editoras Universitárias têm aqui um importante papel a desempenhar. Entretanto, é preciso reconhecer que o impedimento maior está ainda na ausência de uma política editorial nas universidades, o que permite que cada diretor pense projetos que, ainda que brilhantes, atendem às vezes a interesses tão pessoais que dificilmente se sustentam após a saída de seus autores. Nesse sentido, talvez atendam melhor a uma "função cultural" as editoras privadas, já que - como lembra Ortiz (1988:29), "entre nós, as contradições de uma cultura artística e outra de mercado não se manifestam de forma antagônica". E nós nos arriscamos a dizer: artística, mas também literária, científica e tecnológica.

Para completar, deve-se lembrar, ainda, que as Editoras Universitárias, institucionais ou privadas, precisam contribuir para a cultura universitária autêntica e não para aquela voltada à indústria cultural, que resulta do "bombardeio publicitário" - que "deixa de fora o que não é imediatamente mercantil", como recentemente nos lembrou Milton Santos (2000).

\section{NOTAS}

E-mail das autoras: mcguedes@pucsp.bre gmazzilli@bol.com.br

1. Compreende as editoras universitárias institucionais.

2. O Proedi - Programa de Estímulo à Editoração do Trabalho Intelectual das IES Federais, da Secretaria de Ensino Superior, foi concebido por uma "Coordenação de modernização administrativa" que, em 1981, definiu dotação especial a 11 universidades, selecionadas de modo a representar as diferentes regiões do país.

3. Muito desta descrição resulta apenas da experiência pessoal de uma das autoras, freqüentando os Seminários Nacionais desde 1985, vice-presidente na primeira diretoria da Abeu e respondendo pela organização do estande das Editoras Universitárias nas reuniões anuais da SBPC em 1985, 1987 e 1996 e na Bienal Internacional do Livro em São Paulo de 1986 a 1992. Para mais informações, ver os trabalhos de Bufrem (1990) e Da Costa (1992).

4. Salim Miguel, além de escritor (acaba de publicar seu 19ำ livro), é jornalista e tinha, quando foi contratado, experiência em revista literária, de cuja criação e direção participara ativamente no Rio de Janeiro.

\section{REFERÊNCIAS BIBLIOGRÁFICAS}

ANUÁRIO EDITORIAL BRASILEIRO 1998. Editoras (Banco de dados). São Paulo, Cone Sul, 1999.

AZEVEDO, J.E. III Seminário Nacional das Editoras Universitárias. Anais... Campinas, Editora da Unicamp, 1986.

III SEMINÁRIO NACIONAL DAS EDITORAS UNIVERSITÁRIAS. Anais... Campinas, Editora da Unicamp, 1986. 
BUFREM, L.S. Editoras Universitárias no Brasil: uma crítica para reformulação da prática. Tese de doutoramento. São Paulo, Escola de Comunicações e Artes, Universidade de São Paulo, 1990.

CAMPOS, J. III Seminário Nacional das Editoras Universitárias. Anais... Campinas, Editora da Unicamp, 1986.

CATÁLOGO. Editoras Universitárias na III Bienal do Rio. São Paulo, Educ, 1986.

COSTA, G.J. da. "Diferença entre editoras universitárias e editoras na universidade". III Seminário Nacional das Editoras Universitárias. Anais... Campinas, Editora da Unicamp, 1986.

CRENI, G. Os artesãos do livro como alternativa editorial. Dissertação de mestrado. São Paulo, Faculdade de Filosofia, Letras e Ciências Humanas, Universidade de São Paulo, 1997.

DA COSTA, F.M.D. Produção do livro universitário: cultura de elite ou indústria cultural? Dissertação de mestrado. São Paulo, Escola de Comunicação e Artes, Universidade de São Paulo, 1992.

LIMA, E.R. de. "As editoras universitárias no Brasil". Editoras Universitárias: problemas e soluções (um enfoque interamericano). Recife, Editora Universitária da UFPe, 1989.
MIGUEL, S. III Seminário Nacional das Editoras Universitárias. Anais... Campinas, Editora da Unicamp, 1986.

ORTIZ, R. A moderna tradição brasileira: cultura brasileira e indústria cultural. São Paulo, Brasiliense, 1988.

PINSKY, J. III Seminário Nacional das Editoras Universitárias. Anais... Campinas, Editora da Unicamp, 1986

PROEDI/SESU/MEC. Programa de Estímulo à Editoração Universitária dos IES Federais. Brasília, Sesu/MEC, 1981.

RODRIGUES, A. "Atividade editorial como extensão do ensino e da pesquisa". III Seminário Nacional das Editoras Universitárias. Anais... Campinas, Editora da Unicamp, 1986.

SANTOS, M. Folha de S.Paulo. São Paulo, Caderno Mais, 1 de março de 2000.

STUMPF, I.R.C. Revistas universitárias. Projetos inacabados. Tese de doutoramento. São Paulo, Escola de Comunicação e Artes, Universidade de São Paulo, 1994.

O ESTADO DE S. PAULO. "Editoras e Universidades". São Paulo, Editorial, 27 de julho de 1991. 